\title{
Selective Aerobic Oxidation of Benzyl Alcohols with Palladium(0) Nanoparticles Suspension in Water
}

\author{
Dolorès Bourbiaux $^{1} \cdot$ Stéphane Mangematin ${ }^{1} \cdot$ Laurent Djakovitch $^{1} \cdot$ Franck Rataboul $^{1}$
}

\begin{abstract}
This study concerns one of the rare applications of a suspension of palladium nanoparticles in water for oxidation reactions. The aqueous suspension containing well dispersed nanoparticles of $3.85 \mathrm{~nm}$ was obtained following a straightforward procedure involving the reduction of $\mathrm{Na}_{2} \mathrm{PdCl}_{4}$ with $\mathrm{NaBH}_{4}$ in the presence of PVP as stabilizing agent. In the way of oxidative catalytic valorisation of lignin, the aqueous suspension was directly applied as catalytic medium for the selective oxidation of vanillic alcohol into vanillin $\left(80{ }^{\circ} \mathrm{C}, \mathrm{O}_{2}, 1 \mathrm{~h}\right)$ with more than $90 \%$ yield. Reusability of the catalytic medium has been demonstrated, acting as "quasi-homogeneous catalyst". More sophisticated lignin-derived substrates like veratryl alcohol and hydrobenzoin gave yields of 50-80\% to the respective aldehyde and ketone. In parallel, this as-synthesized suspension was directly used to prepare a $\mathrm{Pd} / \mathrm{TiO}_{2}$ catalyst, the latter showing less efficiency for the catalytic transformations.
\end{abstract}

\section{Graphic Abstract}<smiles>COc1cc(CO)ccc1O</smiles>

vanillic alcohol

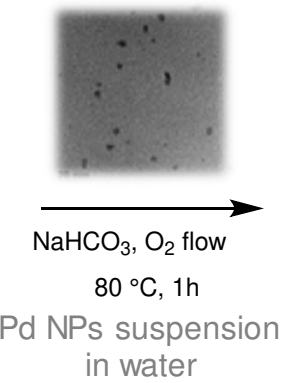

in water<smiles>COc1cc(C=O)ccc1O</smiles>

vanillin $90 \%$ yield

Keywords Metallic nanoparticles · Catalysis · Alcohols oxidation $\cdot$ Aqueous suspension

\section{Introduction}

The catalytic oxidation of alcohols is an important reaction giving aldehydes, ketones and carboxylic acids as valuable compounds for the chemical industry. Molecular catalysts and organic media are often used for this transformation. Besides, metal nanoparticles (NPs), particularly deposited on a support, are of great potential for oxidation reactions

Franck Rataboul

franck.rataboul@ircelyon.univ-lyon1.fr

1 Univ Lyon, Université Claude Bernard Lyon 1, CNRS, IRCELYON, 69626 Villeurbanne, France
[1,2] and $\mathrm{Pd}$ is one of the most interesting metals [3-5]. Such heterogeneous catalysts are particularly powerful to conduct oxidations in environmentally friendly conditions, i.e. in water using oxygen or air as oxidant, especially if water is the solvent to implement both catalyst preparations and catalytic reactions.

Considering this general context of sustainable chemistry the oxidation of biosourced substrates like lignin is of great potential for the production of molecules of interest. Indeed lignin is a direct renewable source of aromatics and in recent years many studies reported its catalytic valorization under oxidative atmosphere giving oxygenated aromatics [6-8]. The oxidative transformation of lignin 
generally leads to vanillin and related products through the oxidative cleavage of benzylic functions present in the substrate structure $[9,10]$.

More generally, recent examples reported the aerobic oxidation of benzyl alcohols in water using Pd-based heterogeneous catalysts. For instance $\operatorname{Pd}(0)$ nanoparticles supported on a polymer have been directly prepared by the polymerization of the Pd-containing methacrylate monomer giving selective formation of aldehydes or ketones [11]. More recently bimetallic Au-Pd NPs supported on alumina showed higher activity than the monometallic NPs for the selective oxidation of various benzyl alcohol derivatives [12]. $\operatorname{Pd}(0)$ NPs deposited on mesoporous carbon nanocomposites correspond to a rare example of catalyst oxidizing benzyl alcohols to the corresponding carboxylic acids [13]. Beside these supported-metal catalysts, a recent approach based on metal suspensions in a solvent gives dispersed (colloidal) nanoparticles having catalytic behaviour often considered as "quasi-homogeneous" [14-17]. If water is used as solvent, a stabilizer soluble in water is required and several systems have been reported to date especially for noble metals [18]. In the case of $\mathrm{Pd}$ aqueous suspensions, Pd chloride salts are often used as precursors in the presence of water soluble stabilizers like polymers (polyvinyl alcohol, polyvinyl pyrrolidone, polyethylene diamine, polystyrene, polyethylene glycol) [19-23], short- and long-chain surfactants [24, 25], calixarenes, cyclodextrins [26, 27], natural ligand (glucose, starch, proteins) [28-30] and P- or P-O-based ligands [31, 32]. As for heterogeneous catalysts, the main influencing synthesis parameters are the metal precursor, the solvent, and the stabilizing system. Preparations are generally onepot (direct) procedures but very different conditions have been applied, leading to $\operatorname{Pd}(0) \mathrm{NPs}$ through the presence of a reductant such as a base, hydrogen, the stabilizer, and most often $\mathrm{NaBH}_{4}$. Examples of the formation of $\mathrm{Pd}(\mathrm{II})$ NPs have also been reported from thermal decomposition of preformed Pd complexes with water-soluble ligands [33]. The application of these Pd aqueous suspensions falls largely in the fields of $\mathrm{C}-\mathrm{C}$ couplings and to a lesser extent of hydrogenations. It appears to the best of our knowledge that rare examples exist for oxidation reactions in water [34-37].

We wish to report here a straightforward synthesis of $\mathrm{Pd}$ catalyst in the form of nanoparticles dispersed in water. The catalytic potential of these suspensions was assessed through oxidation reactions, rarely reported to date with Pd NPs water suspensions. We particularly studied the selective oxidation of benzylic alcohols as lignin model molecules. Indeed studies related to lignin oxidation often involve model molecules to discuss structure/reactivity of novel catalytic systems and highlight the importance of reaction parameters [38, 39].

\section{Experimental Section}

\subsection{Chemicals}

All reactants, reagents and products were used as received from Sigma Aldrich except $\mathrm{TiO}_{2} \mathrm{P} 25$ (specific surface area $57 \mathrm{~m}^{2} \mathrm{~g}^{-1}$ ) obtained from Evonik.

\subsection{Synthesis of Pd NPs in Water}

A first solution was prepared by dissolving $\mathrm{Na}_{2} \mathrm{PdCl}_{4}$ (21 mg, $\left.7.05 \times 10^{-5} \mathrm{~mol} \mathrm{Pd}\right)$ in HPLC-grade water $(8 \mathrm{~mL})$ at room temperature. A second solution was prepared by dissolving PVP K30 (MW 40,000, 78 mg, 10 equiv./ $\mathrm{Pd})$ in HPLC-grade water $(8 \mathrm{~mL})$ at room temperature. Both solutions were mixed and stirred for $30 \mathrm{~min}$. A third solution of $\mathrm{NaBH}_{4}(6.7 \mathrm{mg}, 2.5$ equiv./Pd) in $4 \mathrm{~mL}$ of HPLC-grade water was quickly added into the previous mixture, leading to colour change from yellow to black. The obtained colloidal suspension of Pd nanoparticles ( $0.035 \mathrm{~mol} \mathrm{~L}^{-1}$ of Pd) was stable over time and could be used for catalytic reactions $24 \mathrm{~h}$ after synthesis.

\subsection{Synthesis of Pd NPs on $\mathrm{TiO}_{2}$}

$\mathrm{Pd} / \mathrm{TiO}_{2}$ was prepared by immobilisation of preformed Pd nanoparticles (see above). Prior to impregnation, the colloidal suspension of Pd NPs was adjusted to $\mathrm{pH} 2$ by addition of $\mathrm{HCl}\left(10 \%\right.$ in HPLC-grade water). $\mathrm{TiO}_{2} \mathrm{P} 25$ $(750 \mathrm{mg}$ ) was then added and the mixture was stirred for $1 \mathrm{~h}$ at room temperature. The solid was filtered on Büchner, dried overnight $\left(120^{\circ} \mathrm{C}\right)$, and calcined under air flow $\left(450{ }^{\circ} \mathrm{C}, 2{ }^{\circ} \mathrm{C} \mathrm{min}{ }^{-1}, \mathrm{~N}_{2} / \mathrm{O}_{2} 80 / 20,60 \mathrm{~mL} \mathrm{~min}{ }^{-1}\right)$ for $3 \mathrm{~h}$. Reduction under $\mathrm{H}_{2}$ flow $\left(300{ }^{\circ} \mathrm{C}, 2{ }^{\circ} \mathrm{C}\right.$ min $^{-1}$, $60 \mathrm{~mL} \mathrm{~min}^{-1}$,) for $3 \mathrm{~h}$ followed by passivation with $1 \%$ $\mathrm{O}_{2} / \mathrm{N}_{2}\left(60 \mathrm{~mL} \mathrm{~min}^{-1}\right)$ for $30 \mathrm{~min}$ at room temperature led to a solid with $2.18 \mathrm{wt} \%$ of Pd.

\subsection{Nanoparticle Size Determination}

Suspended and supported Pd NPs were characterized using transmission electron microscopy on Jeol 2010 apparatus with LaB6 tip at $200 \mathrm{kV}$. For analysis, a dispersion of the sample crushed in ethanol was deposited on standard holey carbon-covered copper TEM grids. Metal particle size distributions have been determined using FIDJI image program from the measurement of around 200 particles in arbitrarily chosen areas from the images. 


\subsection{Pd Content Determination}

Pd content was determined with an ICP-OES Activa from Horiba Jobin Yvon apparatus. The sample was dissolved with $\mathrm{HCl} / \mathrm{HNO}_{3}$ followed by complete water evaporation before heating further the residue in $\mathrm{HCl}$.

\subsection{Crystallinity Determination}

Powder X-ray diffraction patterns were obtained on a Bruker D5005 spectrometer using a radiation $\mathrm{Cu}-\mathrm{K} \alpha$ $(\lambda=1.054184 \AA)$. Analysis was performed with DIFFRAC. EVA program.

\subsection{Vanillic Alcohol, Veratryl Alcohol and Hydrobenzoin Oxidations}

The reactions were performed in a $100 \mathrm{~mL}$ round-bottomed flask. A colloidal suspension of PVP stabilized Pd NPs ( $20 \mathrm{~mL}, 7.05 \times 10^{-5} \mathrm{~mol}$ of $\mathrm{Pd}$ ), or a dispersion of $\mathrm{Pd} / \mathrm{TiO}_{2}$ (277 mg, $7.05 \times 10^{-5} \mathrm{~mol} \mathrm{Pd}$ ) in $20 \mathrm{~mL}$ of HPLC-grade water, was introduced in the flask. $\mathrm{NaHCO}_{3}(400 \mathrm{mg})$ was added and the mixture heated at $80{ }^{\circ} \mathrm{C}$ under vigorous stirring. The reactant $\left(7.05 \times 10^{-3} \mathrm{~mol}\right.$ for vanillic and veratryl alcohol, 100 equiv./Pd or $7.05 \times 10^{-4} \mathrm{~mol}$ for hydrobenzoin, 10 equiv./Pd) was then added. The mixture was heated at the desired temperature stirred under air or $\mathrm{O}_{2}$ flow, for a determined time with regular sampling for analysis.

\subsection{Conversion and Yield Determination}

Conversion and yields were determined using a Shimadzu GC-2030 gas chromatograph equipped with a FID detector (Phenomenex Zebron ZB-5HT column, He as carrier gas, $\mathrm{T}$ injection $300^{\circ} \mathrm{C}$, T detection $250{ }^{\circ} \mathrm{C}$ ). Samples were prepared from regular sampling of $500 \mu \mathrm{L}$ aliquots. Prior to analysis, aqueous samples were extracted with $1 \mathrm{~mL}$ of organic solvent (ethyl acetate for vanillic alcohol or dichloromethane for veratryl alcohol and hydrobenzoin experiments), in the presence of $\mathrm{NaCl}(200 \mathrm{mg})$. Yields are molar yields and determined through calibration of commercial samples with decane as external standard.

\subsection{Recycling Experiments}

After a first run, the organics were extracted with $5 \mathrm{~mL}$ of ethyl acetate ( 5 successive times) from the reaction medium until no vanillic alcohol nor vanillin were observed on GC analysis. Then a new charge of vanillic alcohol was added to the obtained aqueous phase and a second run was performed under identical conditions. This procedure was repeated for successive catalyst recycling.

\section{Results and Discussion}

\subsection{Synthesis and Characterization of Water Suspensions of $\operatorname{Pd}(0)$ Nanoparticles}

Several examples of dispersion of $\operatorname{Pd}(0)$ NPs in water stabilized by $\mathrm{PVP}$ have been reported, following varied synthetic conditions. Usually $\mathrm{H}_{2} \mathrm{PdCl}_{4}, \mathrm{~K}_{2} \mathrm{PdCl}_{4}$ or $\mathrm{Na}_{2} \mathrm{PdCl}_{4}$ solutions are used as $\mathrm{Pd}$ sources, after conventional [40] or microwave heating [41]. Most often $\mathrm{NaBH}_{4}$ serves as reductant [35, 42, 43] although examples exist using ethanol [41, 44] or even without additional reductant [45] particularly through electrochemical methods [46]. The obtained nanoparticles are of diverse average diameter size depending on the conditions, globally in the $2-5 \mathrm{~nm}$ range.

In the present work, we attempted to identify conditions to present a more straightforward synthetic procedure. In particular, colloidal suspensions were prepared at ambient temperature. Palladium precursor $\mathrm{Na}_{2} \mathrm{PdCl}_{4}$ was dissolved in water along with polyvinylpyrrolidone (PVP). Pd reduction occurred through addition of $\mathrm{NaBH}_{4}$ in water and the mixture was stirred at room temperature. Different preparations were synthesized by varying the stoichiometry of PVP from 5, 10 and 25 molar equivalents (See Sect. 2 for details). This procedure led to colloidal suspensions with $0.035 \mathrm{~mol} \mathrm{~L}^{-1}$ of Pd stable for months under ambient conditions.

As indicated by TEM images (Fig. 1), with PVP/Pd of 5, $\mathrm{Pd}$ particles were obtained with a $3.19 \pm 1.63 \mathrm{~nm}$ average size, which is clearly in line with reported related systems. In this case, it appears that they were encapsulated in PVP micelles but their dispersion was not completely homogeneous. In the case of PVP/Pd of 10, Pd particles possess a mean diameter of $3.85 \pm 0.94 \mathrm{~nm}$ with a homogeneous dispersion. In the presence of 25 equiv. of PVP, the mean diameter was much higher up to $6.64 \pm 1.87 \mathrm{~nm}$, with moreover the presence of aggregates. Therefore, among the three systems, that giving the most dispersed Pd nanoparticles with a relatively small average size was prepared with 10 equiv. of PVP. Therefore, this system was chosen for catalytic studies.

\subsection{Synthesis and Characterization of Pd Nanoparticles Supported on $\mathrm{TiO}_{2}$}

The as-synthetized Pd NPs stabilized by PVP were used to prepare immobilized Pd NPs on $\mathrm{TiO}_{2} \cdot \mathrm{TiO}_{2}$ was chosen since this usual support for heterogeneous catalyst preparation combines structural stability in water and relatively good surface area for Pd NPs immobilisation. The $\mathrm{pH}$ value of the suspension was adjusted to 2 by addition of aqueous $\mathrm{HCl}$ in order to favour ionic interaction with the support. After impregnation, calcination, reduction and passivation steps gave a $\mathrm{Pd} / \mathrm{TiO}_{2}$ material containing $2.18 \mathrm{wt} \%$ of 

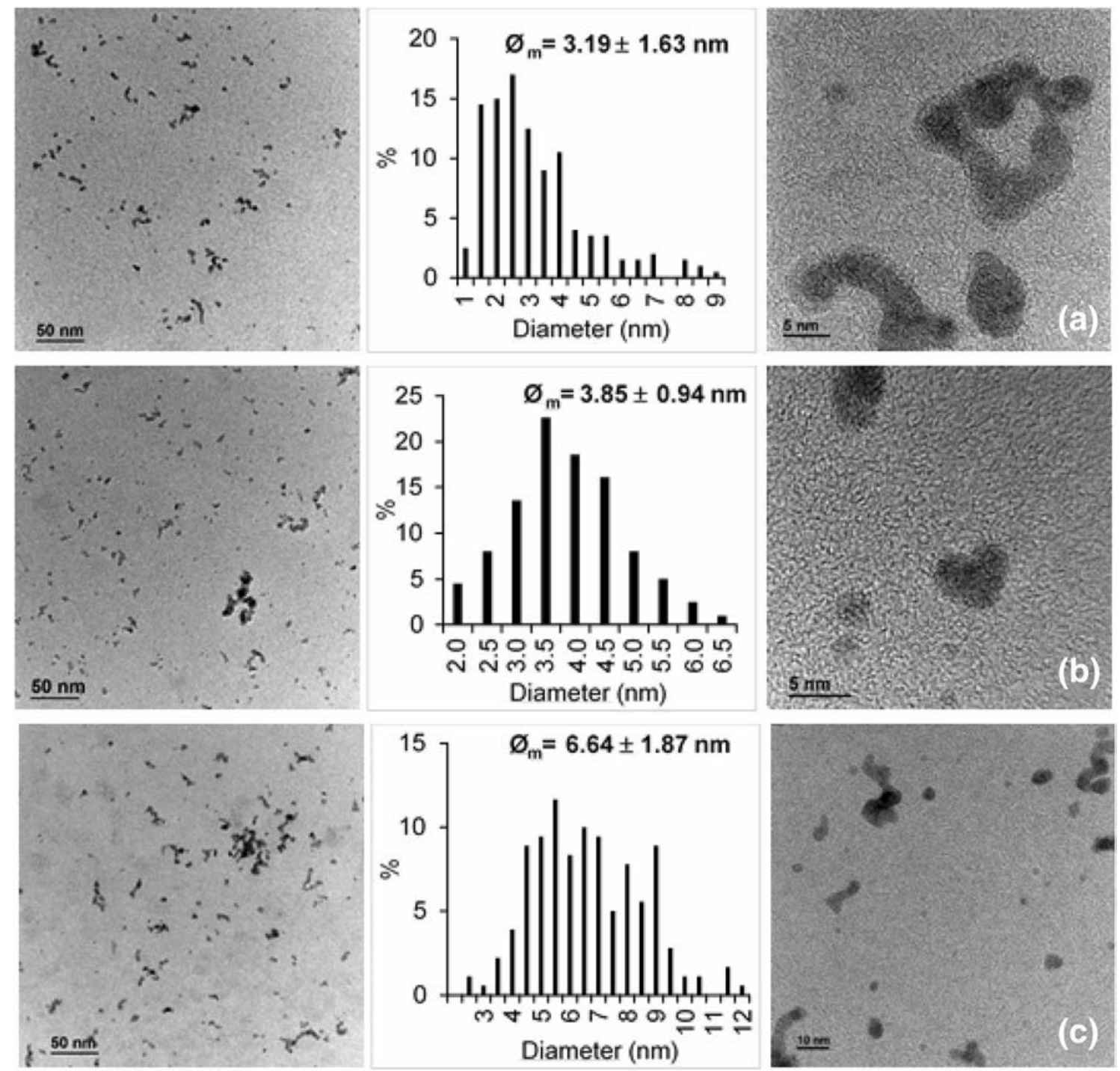

Fig. 1 TEM images and size distribution of Pd NPs prepared with a 5; b 10; $\mathbf{c} 25$ molar equivalents of PVP in water
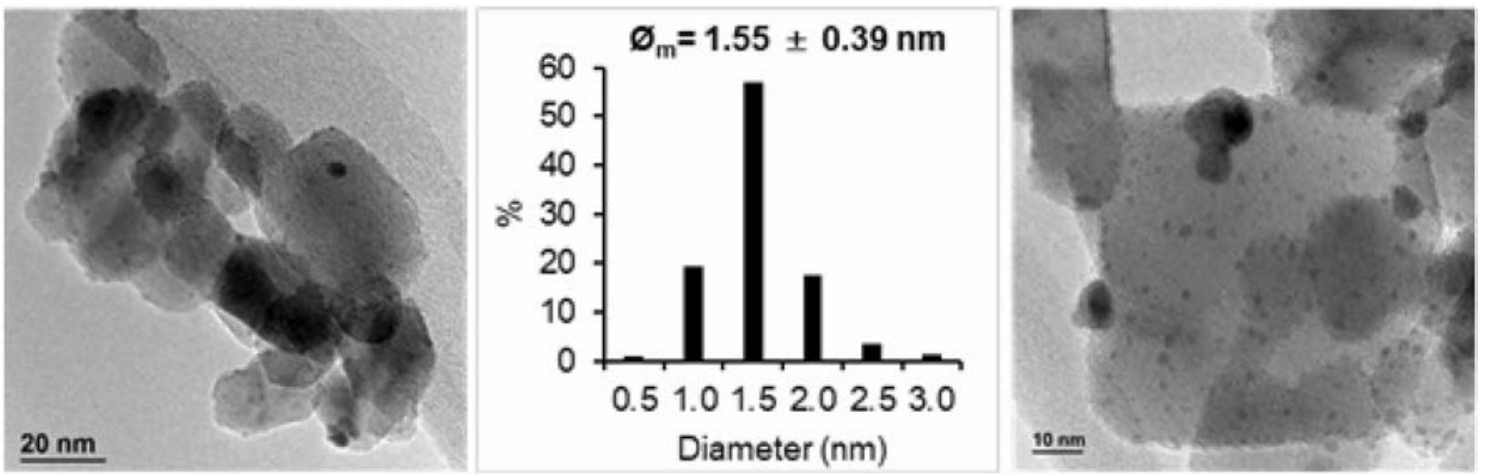

Fig. 2 TEM images and size distribution of Pd NPs deposited on $\mathrm{TiO}_{2}$ 
Pd (see Sect. 2 for details). TEM images (Fig. 2) indicates that the preparation not only preserved the nice dispersion of the original nanoparticles without aggregation but also gave smaller nanoparticles with a mean diameter of $1.55 \pm 0.39 \mathrm{~nm}$.

To explain the presence of smaller particles, we performed a control experiment consisting of acidifying of a colloidal suspension, but without impregnation on $\mathrm{TiO}_{2}$. TEM images (Fig. 3) of the resulting mixture indicates that acidification at $\mathrm{pH} 2.99$ decreased the Pd particle sizes. Further acidification to $\mathrm{pH} 2.65$ led to slight increase of the size. Indexing indicated the formation of a layer of palladium oxychloride during the acidification process. At lower $\mathrm{pH}$ of 2.00, this shell appeared to dissolve, releasing smaller Pd nanoparticles of lower distribution and agglomeration. When supported onto $\mathrm{TiO}_{2}$ those NPs were of even smaller size, certainly due to fast stabilization during deposition on the support.

The BET surface area of this material was $61 \mathrm{~m}^{2} \mathrm{~g}^{-1}$ showing no significant difference compared to $\mathrm{TiO}_{2}$ $\left(57 \mathrm{~m}^{2} \mathrm{~g}^{-1}\right)$. Moreover DRX analysis (Fig. 4) indicates that no modification of $\mathrm{TiO}_{2}$ phases occurred during the synthesis, and as expected due to small particle size, the absence of signals from Pd.

\subsection{Application to the Oxidation of Benzyl Alcohols}

The catalytic properties of Pd NPs stabilised by PVP were evaluated in the oxidation of benzyl alcohols. We first studied the oxidation of vanillic alcohol, a simple lignin model. This substrate was chosen for determining the optimal reaction conditions using Pd NPs prepared with 10 equiv. of
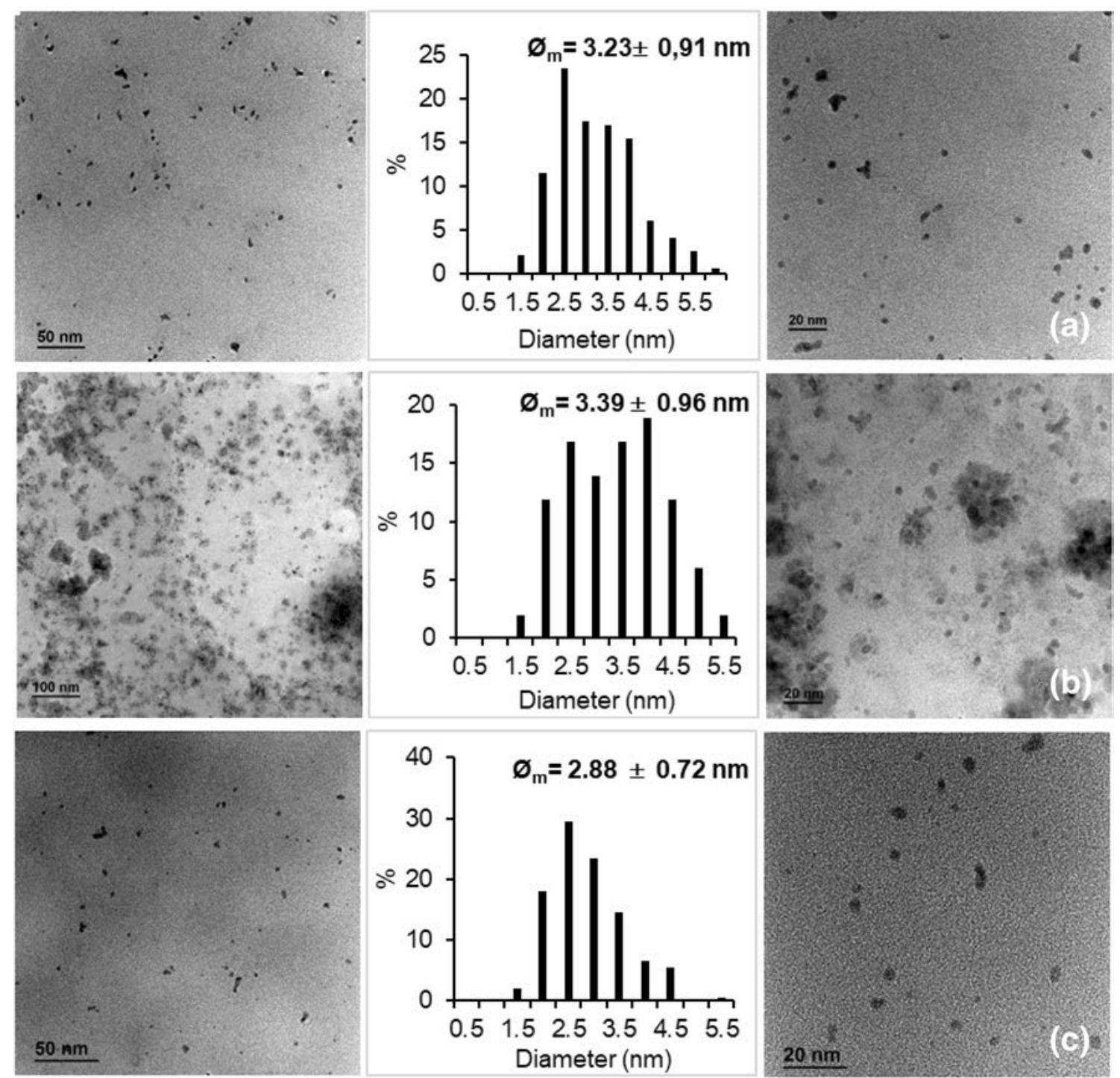

Fig. 3 TEM images and size distribution of Pd NPs after progressive acidification of the suspension, a pH 2.99; b pH 2.65; $\mathbf{c}$ pH 2.00 


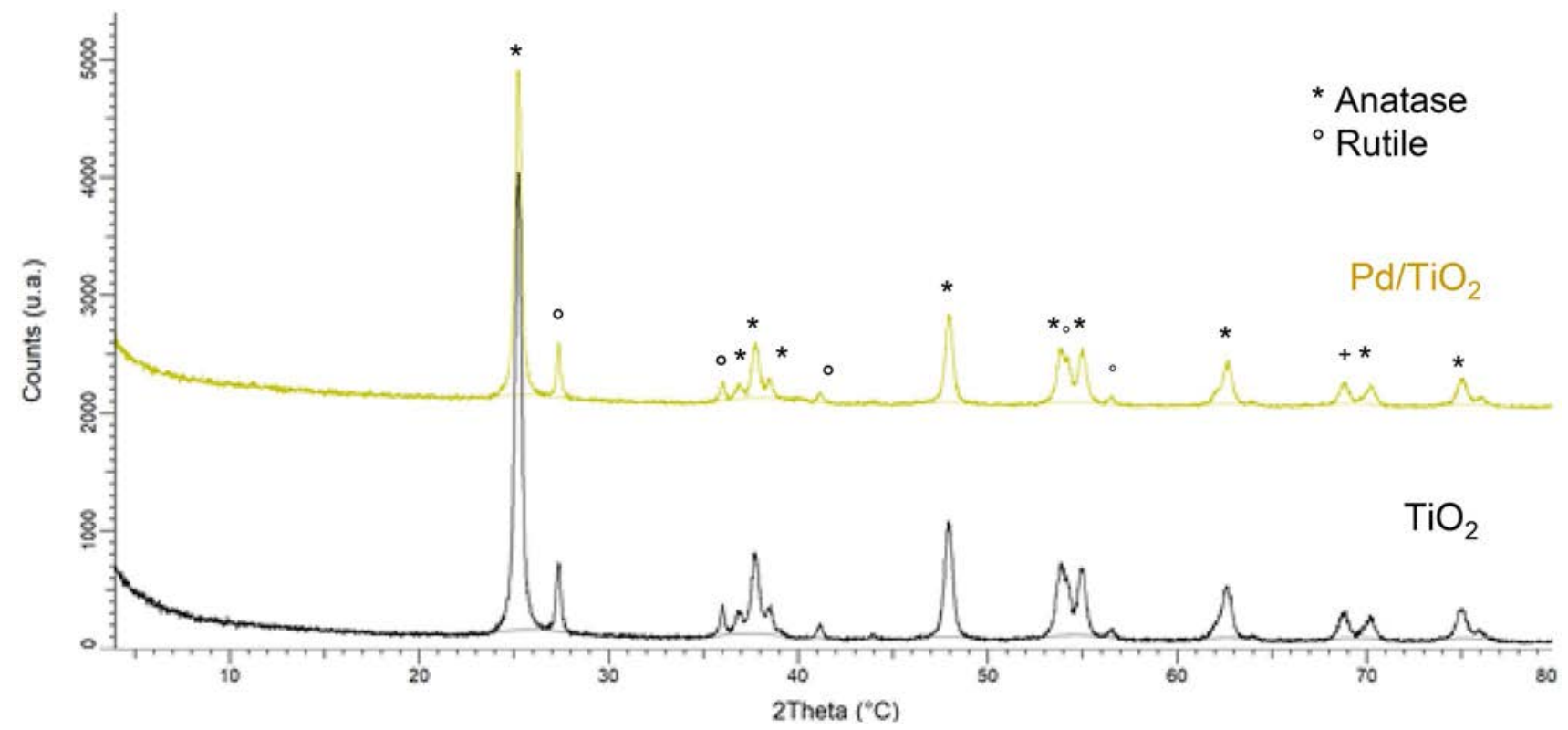

Fig. 4 X-ray diffractograms of $\mathrm{TiO}_{2}$ and $\mathrm{Pd} / \mathrm{TiO}_{2}$

PVP. Oxidation of vanillic alcohol can theoretically form the corresponding aldehyde (vanillin) and carboxylic acid (vanillic acid). Note that the latter is rarely formed over classical metallic catalysts [47] while most often obtained with enzymatic catalysts [48] (Scheme 1).

First set of experiments were performed under air flow at 50 and $80{ }^{\circ} \mathrm{C}$, with or without $\mathrm{NaHCO}_{3}$ as base. These conditions were not optimized and realized to observe first tendencies as presented in Fig. 5. Thus, in the absence of a base the transformation was quite efficient for the formation of vanillin with yield of 90-95\% after $8 \mathrm{~h}$. The temperature had only a slight influence at the beginning but allows as expected a faster global transformation at $80{ }^{\circ} \mathrm{C}$. The presence of $\mathrm{NaHCO}_{3}$, despite giving close apparent initial rate of reaction, increased significantly the reaction time for maximum vanillin formation. The presence of the base can deactivate the catalyst, or led more probably after a certain time to uncontrolled reactivity of vanillin, successively to its continuous formation. A control experiment confirmed that vanillin was not stable in such conditions after expanded reaction time. Indeed, vanillin treated in the same condition was converted up to $75 \%$ after $15 \mathrm{~h}$. As for the experiments performed in the absence of a base, no vanillic acid was observed, excluding therefore this way of transformation. Although we could not definitively identify corresponding products one can propose for example vanillin degradation through aromatic ring opening or even condensation to higher molecular mass compounds [49].

These first results indicate that the Pd NPs aqueous suspension is catalytically active for oxidation reactions and a fine tuning of the conditions has appeared necessary for a more efficient transformation. Therefore we performed the reaction in the presence of $\mathrm{O}_{2}$ atmosphere in place of air to assess possible balance of reaction time and oxidant<smiles>COc1cc(CO)ccc1O</smiles>

vanillic alcohol

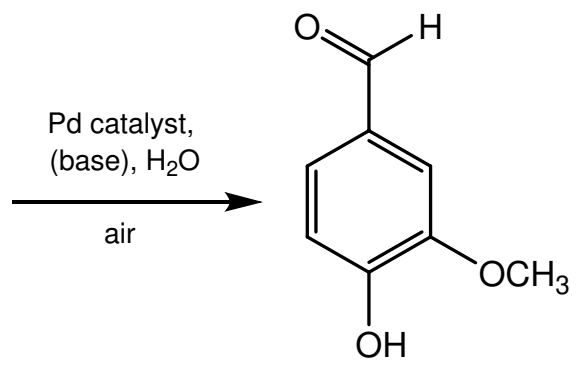

vanillin<smiles>COc1cc(C(=O)O)ccc1O</smiles>

vanillic acid

Scheme 1 Vanillic alcohol oxidation 


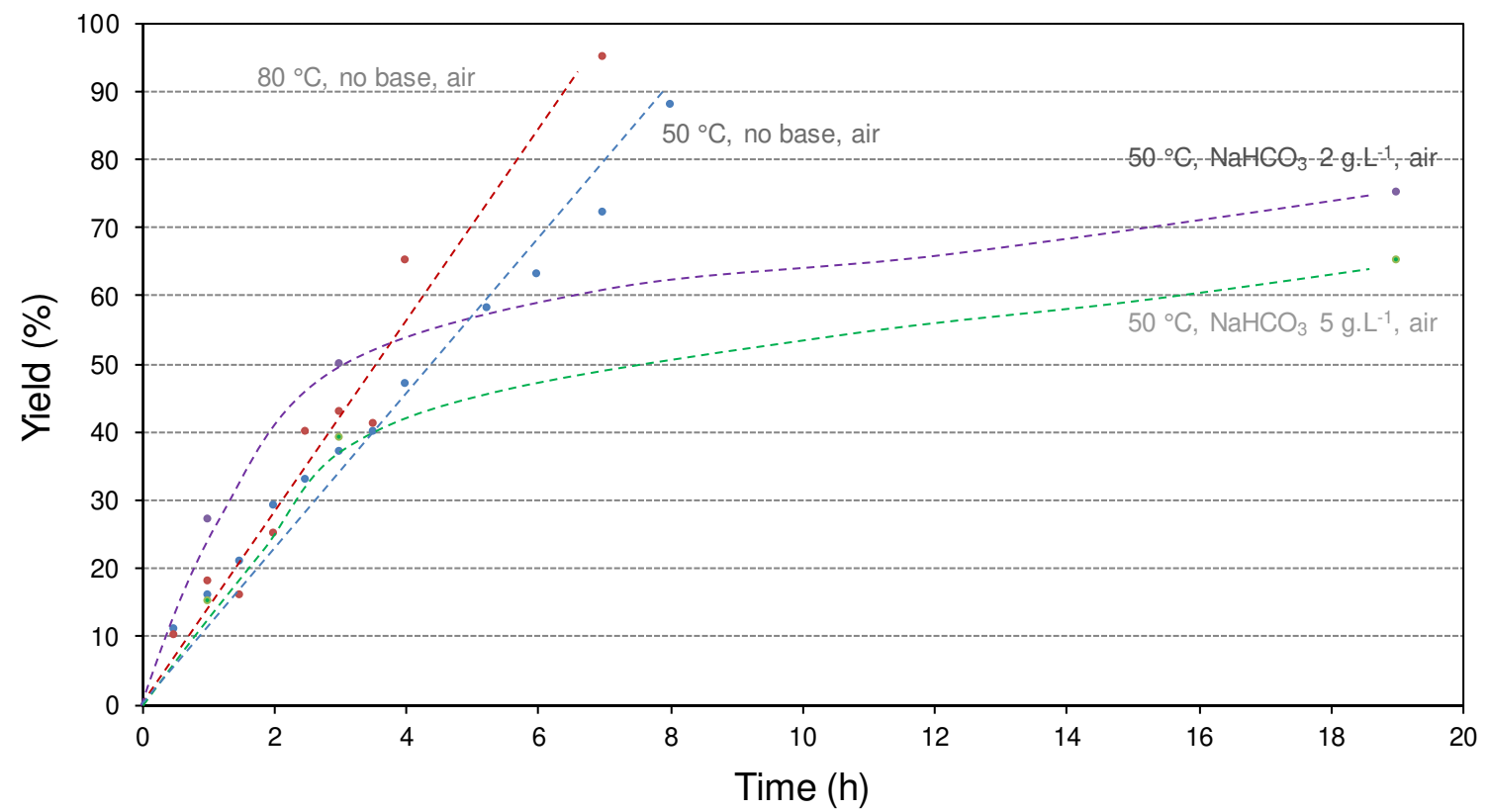

Fig. 5 Vanillic alcohol oxidation with Pd NPs stabilized by PVP under air

Table 1 Vanillic alcohol oxidation with Pd NPs stabilized by PVP under $\mathrm{O}_{2}$

\begin{tabular}{llllc}
\hline Entry & Time $(\mathrm{h})$ & $\mathrm{T}\left({ }^{\circ} \mathrm{C}\right)$ & $\begin{array}{l}\mathrm{NaHCO}_{3} \\
\left(\mathrm{~g} \mathrm{~L}^{-1}\right)\end{array}$ & $\begin{array}{l}\text { Yield of } \\
\text { vanillin } \\
(\%)^{\mathrm{a}}\end{array}$ \\
\hline 1 & 3 & 80 & 0 & 100 \\
2 & 3 & 80 & 5 & 65 \\
3 & 6 & 80 & 10 & 100 \\
4 & 1 & 80 & 20 & 91 \\
$5^{\mathrm{b}}$ & 1 & 80 & 20 & 80 \\
$6^{\mathrm{b}}$ & 1 & 80 & 20 & 66 \\
$7^{\mathrm{c}}$ & 1 & 80 & 20 & 36 \\
\hline
\end{tabular}

$\mathrm{H}_{2} \mathrm{O}(20 \mathrm{~mL})$; substrate $100 \mathrm{~mol}$ equiv./Pd; $\mathrm{Pd}: 7.05 \times 10^{-5} \mathrm{~mol}$; air flow, ambient pressure

${ }^{\text {a }}$ Maximum yield observed

${ }^{\mathrm{b}} 1$ st and 2 nd recycling

${ }^{\mathrm{c}}$ In the presence of $\mathrm{Pd} / \mathrm{TiO}_{2}$

concentration. Thus in this second set of experiments, various conditions under $\mathrm{O}_{2}$ were evaluated (Table 1). Interestingly in the absence of a base, a complete vanillin formation was obtained at $80^{\circ} \mathrm{C}$ within a much shorter reaction time of $3 \mathrm{~h}$ (entry 1) than using air as oxidant. This clearly confirms the positive influence of $\mathrm{O}_{2}$ concentration. Next, the presence of a base gave results somewhat difficult to rationalize (entries 2-4). While lowest concentrations of 5 and $10 \mathrm{~g} \mathrm{~L}^{-1}$ did not seem to influence the reaction, even at longer reaction times, the presence of $20 \mathrm{~g} \mathrm{~L}^{-1}$ allowed a very fast transformation and a yield up to $91 \%$ could be obtained after $1 \mathrm{~h}$ (entry 4). Note that at this level of base concentration, a noticeably short reaction time was mandatory since a decrease of vanillin yield was also clearly observed while keeping reaction running, as discussed above.

All these tendencies indicate the efficiency of this easily prepared aqueous suspension of Pd nanoparticles as catalyst without the need of purification of catalyst synthesis medium. In the literature there are not many reports of the aerobic oxidation of vanillic alcohol into vanillin with Pd-based catalysts. Examples with supported Pd such as $\mathrm{Au}-\mathrm{Pd} / \mathrm{C}$ (or HT) [50], $\mathrm{Au}-\mathrm{Pd} / \mathrm{TiO}_{2}$ [51], Pd/MIL-101 [52], $\mathrm{Pd} / \mathrm{MgO}$ [53], $\mathrm{Pd} / \mathrm{MCF}$ [54] or $\mathrm{Pd} / \mathrm{Cu}$-chlorophosphate [55] gave interesting results at temperatures from 25 to $170{ }^{\circ} \mathrm{C}$, however in organic solvents like dioxane, toluene or alcohols. It seems that the only example of this reaction in water using single Pd metal was performed using an immobilized $\mathrm{Pd}(0)$-pyridyl-based molecular complex on SBA-15 giving $99 \%$ yield of vanillin $\left(80{ }^{\circ} \mathrm{C}, 7 \mathrm{~h}, \mathrm{~N}_{2}\right.$ or air atmosphere, 325 equiv. of $\mathrm{Pd})[12,56]$. Therefore, the present results are clearly in line with reported works.

Recyclability has been studied (see Sect. 2 for details). First, as shown in Fig. 6, the Pd suspension appeared to be stable after reaction since no Pd deposit was observed. Then, the organic products were extracted from the reaction medium with EtOAc leaving the catalytic system in the aqueous phase. After addition of vanillic alcohol only, another run was performed under same conditions. Results indicates that the Pd NPs were still active despite a loss of efficiency (Table 1, entries 5-6). TEM images and size distribution (Fig. 7) of Pd nanoparticles after the third run 
Fig. 6 Liquid phases obtained through catalyst recycling experiments
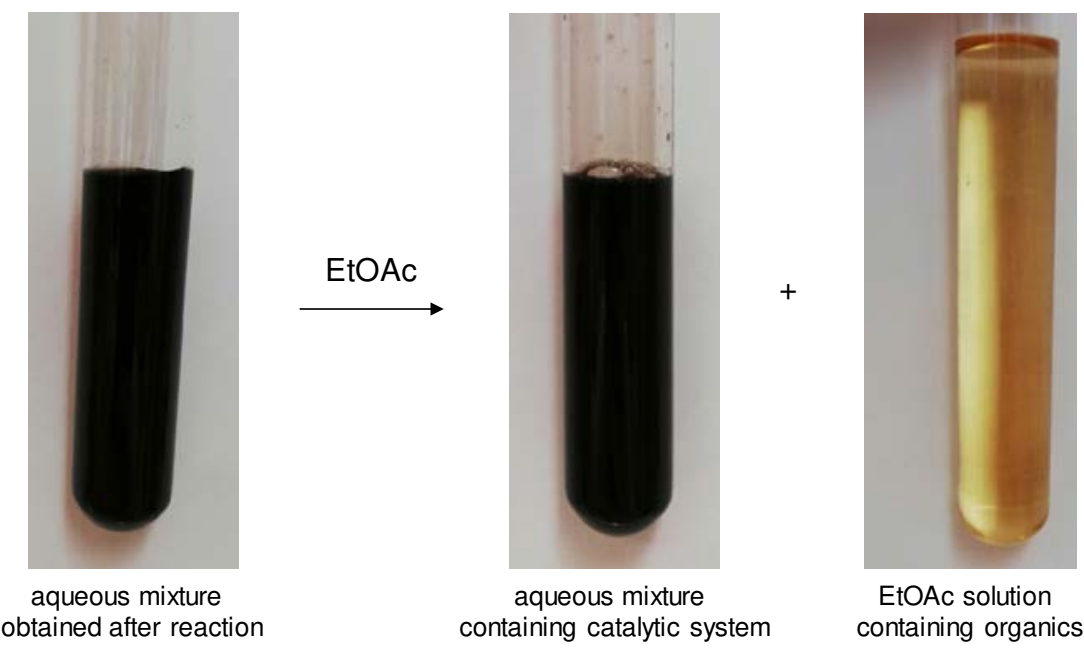

EtOAc solution containing organics
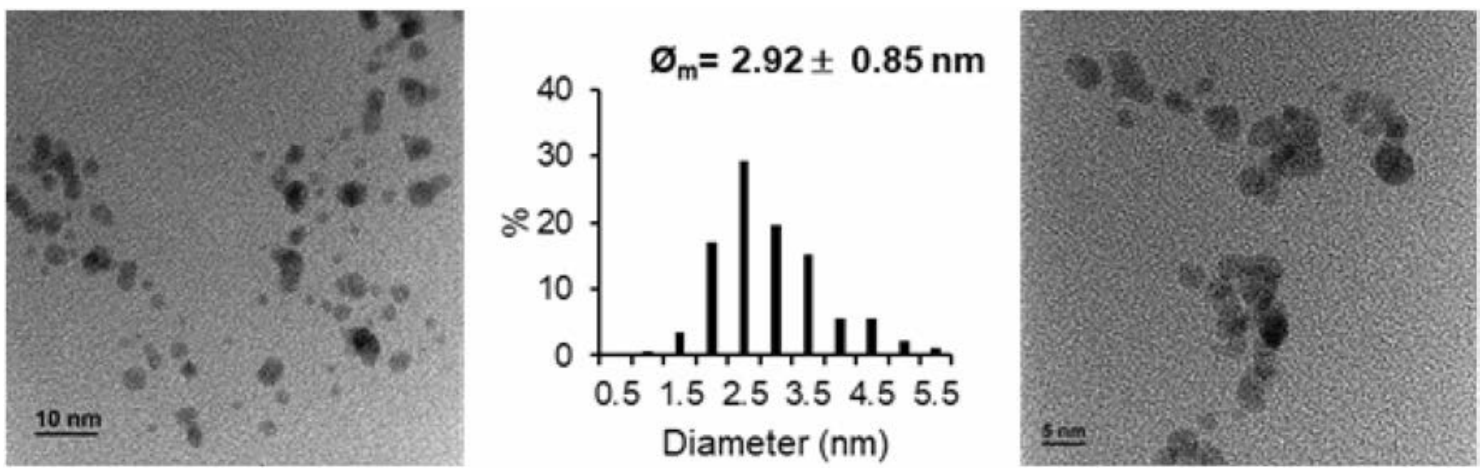

Fig. 7 TEM images and size distribution of Pd NPs after the third run

confirmed the stability of the suspension with well dispersed NPs of $2.92 \pm 0.85 \mathrm{~nm}$ average size, in the same range as before the catalytic reactions. For each recycling, ICP analysis indicates the presence of $0.04 \%$ of initial Pd in the organic solution. Despite the fact that this corresponds to a very light loss of Pd from the original suspension, this may be a possibility for the lesser vanillin formation.

Using these last conditions, the potential of $\mathrm{Pd} / \mathrm{TiO}_{2}$ material prepared from the NPs/PVP nanoparticles was compared to that of the parent NPs/PVP suspension (Table 1, entry 7). Here a significant lower efficiency led to a moderate maximum yield of $36 \%$ after $1 \mathrm{~h}$.

Based on this, the potential of the NPs suspension was assessed for the oxidation of other substrates modelling the lignin structure under the same conditions [57] (Table 2). First we observed that the reaction was less efficient using 2-methoxybenzyl alcohol (entry 1 ) with a maximum yield of $21 \%$. Here the presence of a methoxy substituent at the ortho position partly prevents the transformation. This phenomenon has been recently observed with Pd-catalysts under similar conditions and steric hindrance was given as the reason for this lower reactivity [58, 59]. Veratryl alcohol oxidation was rarely reported using Pd catalysts, even more with $\mathrm{O}_{2}$ as oxidant [60-65]. Here, veratryl alcohol reacted similarly to vanillic alcohol with the Pd NPs suspension leading to $83 \%$ of veratraldehyde after $2 \mathrm{~h}$ (entry 2 ). This is not surprising since veratryl alcohol structure only slightly differs from vanillic alcohol. Hydrobenzoin is a more sophisticated reactant having vicinal secondary alcohol functions as can be encountered within the lignin structure. Here, it was possible to obtain $58 \%$ of benzoin with nice selectivity after $5 \mathrm{~h}$ with the Pd NPs suspension (entry 3 ). Therefore no $(\mathrm{PhCO})_{2}$ benzil nor $\mathrm{C}-\mathrm{C}$ cleavage products (e.g. benzaldehyde) were observed. While some reports exist with for example homogeneous $\mathrm{Mn} / \mathrm{H}_{2} \mathrm{O}_{2}$ systems $[57,66]$, to the best of our knowledge this is the first example of the oxidation of this compound in the presence of a $\mathrm{Pd} / \mathrm{O}_{2} /$ water system [67-69]. This is encouraging for the transformation of more functionalized substrates.

In all cases the colloidal suspension of $\mathrm{Pd}$ has proven to be much more efficient than $\mathrm{Pd} / \mathrm{TiO}_{2}$ which was particularly not able to transform hydrobenzoin. Note that optimization 
Table 2 2-Methoxybenzyl alcohol, veratryl alcohol and hydrobenzoin oxidation under $\mathrm{O}_{2}$

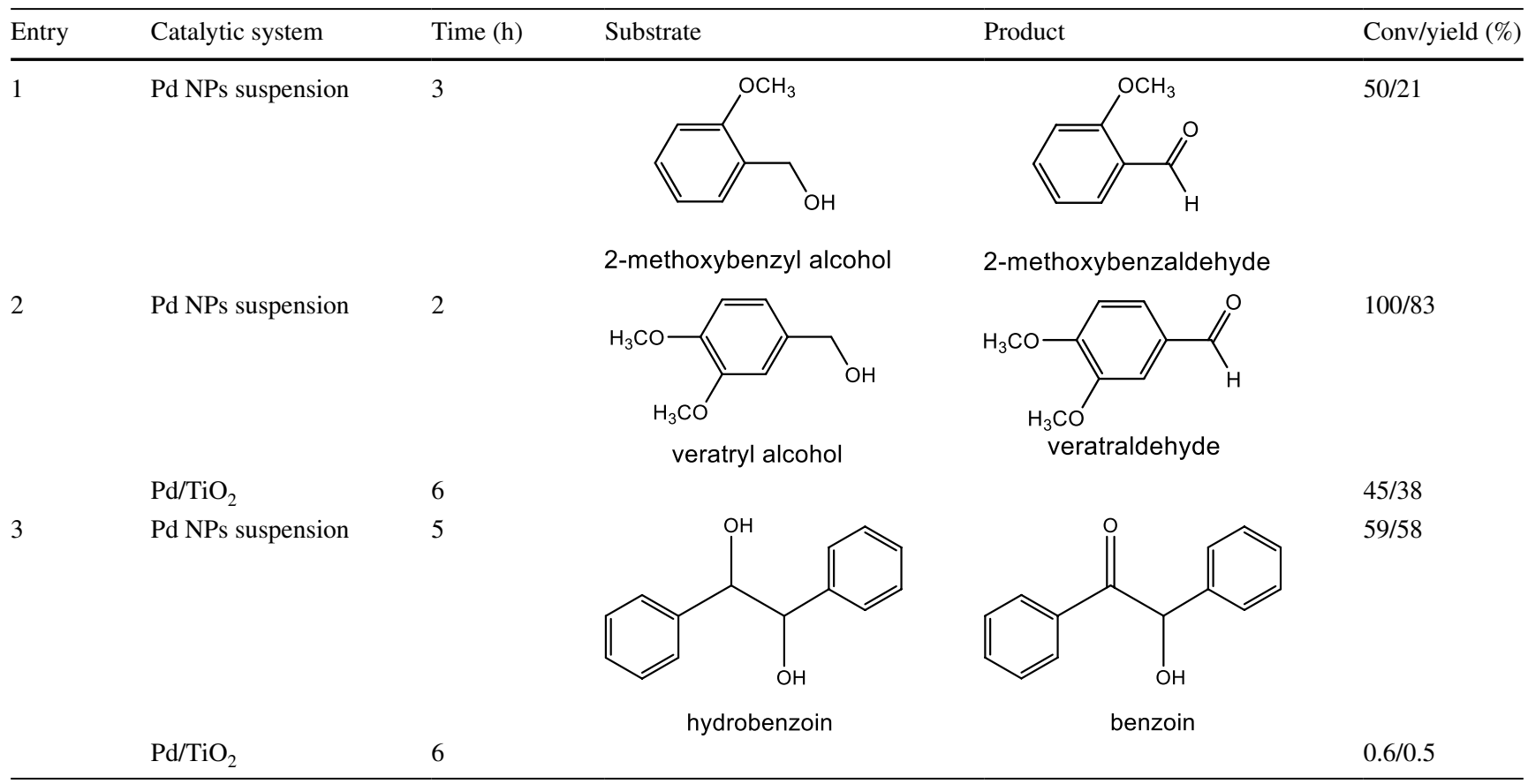

$\mathrm{H}_{2} \mathrm{O}(20 \mathrm{~mL})$; substrate 10 molar equiv./Pd, $\mathrm{Pd}: 7.05 \times 10^{-5} \mathrm{~mol} ; \mathrm{O}_{2}$ flow, $80{ }^{\circ} \mathrm{C}, \mathrm{NaHCO}_{3} 20 \mathrm{~g} \mathrm{~L}^{-1}$, ambient pressure

of conditions has not been attempted with $\mathrm{Pd} / \mathrm{TiO}_{2}$ but these results nevertheless highlight the probably higher accessibility of the Pd nanoparticles dispersed in water than supported on $\mathrm{TiO}_{2}$, and that the particle size of the metal phase appeared to be not an exclusive parameter governing that reactivity.

\section{Conclusion}

We have presented an easy procedure for the synthesis of $\mathrm{Pd}$ nanoparticles in water stabilised by PVP. Nanoparticles of $3.85 \mathrm{~nm}$ with good dispersion were obtained. This mixture was used to prepare $\mathrm{Pd} / \mathrm{TiO}_{2}$ leading to a material having $2.18 \mathrm{wt} \%$ of $\mathrm{Pd}$ in the form of nanoparticles with a mean diameter of $1.55 \pm 0.39 \mathrm{~nm}$. These two systems were used as catalysts for the oxidation of benzyl alcohols as lignin model molecules in water. While $\mathrm{Pd} / \mathrm{TiO}_{2}$ presented relatively low efficiency, Pd nanoparticles suspension showed high potential for vanillic alcohol aerobic oxidation in basic medium under mild conditions of pressure and temperature, with a possibility of catalytic system reuse acting therefore as "quasi-homogeneous catalyst". This system was also efficient for the oxidation of more complex lignin model molecules as veratryl alcohol or hydrobenzoin.

Acknowledgements The authors thank the French National Research Agency for funding through NANOTRAP Project
(ANR-17-CE07-0027). The authors thanks L. Burel (IRCELYON) for precious discussion concerning TEM analysis.

\section{References}

1. Parmeggiani C, Cardona F (2012) Transition metal based catalysts in the aerobic oxidation of alcohols. Green Chem 14:547-564

2. Davis SE, Ide MS, Davis RJ (2013) Selective oxidation of alcohols and aldehydes over supported metal nanoparticles. Green Chem 15:17-45

3. Chan-Thaw CE, Savara A, Villa A (2018) Selective benzyl alcohol oxidation over Pd catalysts. Catalysts 8:431/431-431/421

4. Durndell LJ, Lee AF, Bailie DS, Muldoon MJ (2015) Selective palladium-catalysed aerobic oxidation of alcohols. RSC Green Chem Ser 28:92-132

5. Muzart J (2003) Palladium-catalysed oxidation of primary and secondary alcohols. Tetrahedron 59:5789-5816

6. Bourbiaux D, Pu J, Rataboul F, Djakovitch L, Geantet C, Laurenti D (2021) Reductive or oxidative catalytic lignin depolymerization: an overview of recent advances. Catal Today (Under revision)

7. Sun Z, Fridrich B, de Santi A, Elangovan S, Barta K (2018) Bright side of lignin depolymerization: toward new platform chemicals. Chem Rev 118:614-678

8. Zakzeski J, Bruijnincx PCA, Jongerius AL, Weckhuysen BM (2010) The catalytic valorization of lignin for the production of renewable chemicals. Chem Rev 110:3552-3599

9. Ma R, Guo M, Zhang X (2018) Recent advances in oxidative valorization of lignin. Catal Today 302:50-60

10. Vangeel T, Schutyser W, Renders T, Sels BF (2018) Perspective on lignin oxidation: advances, challenges, and future directions. Top Curr Chem 376:30

11. Dell'Anna MM, Mali M, Mastrorilli P, Cotugno P, Monopoli A (2014) Oxidation of benzyl alcohols to aldehydes and ketones 
under air in water using a polymer supported palladium catalyst. J Mol Catal A 386:114-119

12. Zhang W, Xiao Z, Wang J, Fu W, Tan R, Yin D (2019) Selective aerobic oxidation of alcohols over gold-palladium alloy catalysts using air at atmospheric pressure in water. ChemCatChem 11:1779-1788

13. Ganji N, Karimi B, Najafvand-Derikvandi S, Vali H (2020) Palladium supported on a novel ordered mesoporous polypyrrole/ carbon nanocomposite as a powerful heterogeneous catalyst for the aerobic oxidation of alcohols to carboxylic acids and ketones on water. RSC Adv 10:13616-13631

14. Favier I, Pla D, Gómez M (2020) Palladium nanoparticles in polyols: synthesis, catalytic couplings, and hydrogenations. Chem Rev 120:1146-1183

15. Axet MR, Philippot K (2020) Catalysis with colloidal ruthenium nanoparticles. Chem Rev 120:1085-1145

16. Astruc D, Lu F, Aranzaes JR (2005) Nanoparticles as recyclable catalysts: the frontier between homogeneous and heterogeneous catalysis. Angew Chem Int Ed 44:7852-7872

17. Prati L, Villa A (2014) Gold colloids: from quasi-homogeneous to heterogeneous catalytic systems. Acc Chem Res 47:855-863

18. Denicourt-Nowicki A, Roucoux A (2016) Odyssey in polyphasic catalysis by metal nanoparticles. Chem Rec 16:2127-2141

19. Wang X, Huang C, Li X, Xie C, Yu S (2019) PVA-encapsulated palladium nanoparticles: eco-friendly and highly selective catalyst for hydrogenation of nitrobenzene in aqueous medium. Chem Asian J 14:2266-2272

20. Llevot A, Monney B, Sehlinger A, Behrens S, Meier M (2017) Highly efficient Tsuji-Trost allylation in water catalyzed by Pdnanoparticles. Chem Commun 53:5175-5178

21. Levi N, Neumann R (2013) Diastereoselective and enantiospecific direct reductive amination in water catalyzed by palladium nanoparticles stabilized by polyethyleneimine derivatives. ACS Catal 3:1915-1918

22. Ohtaka A, Teratani T, Fujii R, Ikeshita K, Kawashima T, Tatsumi K, Shimomura O, Nomura R (2011) Linear polystyrene-stabilized palladium nanoparticles-catalyzed $\mathrm{C}-\mathrm{C}$ coupling reaction in water. J Org Chem 76:4052-4060

23. Sawoo S, Srimani D, Dutta P, Lahiri R, Sarkar A (2009) Size controlled synthesis of Pd nanoparticles in water and their catalytic application in $\mathrm{C}-\mathrm{C}$ coupling reactions. Tetrahedron 65:4367-4374

24. La Sorella G, Sperni L, Canton P, Coletti L, Fabris F, Strukul G, Scarso A (2018) Selective hydrogenations and dechlorinations in water mediated by anionic surfactant-stabilized Pd nanoparticles. J Org Chem 83:7438-7446

25. Zhang Y, Zhu J, Xia Y-T, Sun X-T, Wu L (2016) Efficient hydrogenation of nitrogen heterocycles catalyzed by carbon-metal covalent bonds-stabilized palladium nanoparticles: synergistic effects of particle size and water. Adv Synth Catal 358:3039-3045

26. Noel S, Leger B, Ponchel A, Philippot K, Denicourt-Nowicki A, Roucoux A, Monflier E (2014) Cyclodextrin-based systems for the stabilization of metallic $(0)$ nanoparticles and their versatile applications in catalysis. Catal Today 235:20-32

27. Mehta V, Panchal M, Kongor A, Panchal U, Jain VK (2016) Synthesis of water-dispersible Pd nanoparticles using a novel oxacalixarene derivative and their catalytic application in $\mathrm{C}-\mathrm{C}$ coupling reactions. Catal Lett 146:1581-1590

28. Dhara K, Parasar B, Patil AJ, Dash J (2019) Microwave assisted cross-coupling reactions using palladium nanoparticles in aqueous media. Synth Commun 49:859-868

29. Dewan A, Bharali P, Bora U, Thakur AJ (2016) Starch assisted palladium(0) nanoparticles as in situ generated catalysts for room temperature Suzuki-Miyaura reactions in water. RSC Adv 6:11758-11762

30. Prastaro A, Ceci P, Chiancone E, Boffi A, Cirilli R, Colone M, Fabrizi G, Stringaro A, Cacchi S (2009) Suzuki-Miyaura cross-coupling catalyzed by protein-stabilized palladium nanoparticles under aerobic conditions in water: application to a one-pot chemoenzymatic enantioselective synthesis of chiral biaryl alcohols. Green Chem 11:1929-1932

31. Iben Ayad A, Belda Marin C, Colaco E, Lefevre C, Methivier C, Ould Driss A, Landoulsi J, Guenin E (2019) "Water soluble" palladium nanoparticle engineering for $\mathrm{C}-\mathrm{C}$ coupling, reduction and cyclization catalysis. Green Chem 21:6646-6657

32. Ge J, Jiang J, Yuan C, Zhang C, Liu M (2017) Palladium nanoparticles stabilized by phosphine ligand for aqueous phase room temperature Suzuki-Miyaura coupling. Tetrahedron Lett 58:1142-1145

33. Asensio JM, Tricard S, Coppel Y, Andres R, Chaudret B, de Jesus E (2017) Synthesis of water-soluble palladium nanoparticles stabilized by sulfonated $\mathrm{N}$-heterocyclic carbenes. Chem Eur J 23:13435-13444

34. Hou W, Dehm NA, Scott RWJ (2008) Alcohol oxidations in aqueous solutions using $\mathrm{Au}, \mathrm{Pd}$, and bimetallic AuPd nanoparticle catalysts. J Catal 253:22-27

35. Balcha T, Strobl JR, Fowler C, Dash P, Scott RWJ (2011) Selective aerobic oxidation of crotyl alcohol using AuPd core-shell nanoparticles. ACS Catal 1:425-436

36. Giachi G, Oberhauser W, Frediani M, Passaglia E, Capozzoli L, Rosi L (2013) Pd-nanoparticles stabilized by pyridinefunctionalized poly(ethylene glycol) as catalyst for the aerobic oxidation of $\alpha, \beta$-unsaturated alcohols in water. J Polym Sci A 51:2518-2526

37. Matsura VA, Potekhin VV, Ukraintsev VB (2002) Kinetics of hydrogenation and oxidation of benzyl alcohol in the presence of colloid palladium in situ. Russ J Gen Chem 72:105-109

38. Behling R, Valange S, Chatel G (2016) Heterogeneous catalytic oxidation for lignin valorization into valuable chemicals: what results? What limitations? What trends? Green Chem 18:1839-1854

39. Hanson SK, Baker RT (2015) Knocking on wood: base metal complexes as catalysts for selective oxidation of lignin models and extracts. Acc Chem Res 48:2037-2048

40. Dong Y, Jin Y, Wang J, Shu J, Zhang M (2017) Pd nanoparticles stabilized by a simple $\mathrm{pH}$-sensitive $\mathrm{p}$ (acrylamide-co-acrylic acid) copolymer: a recyclable and highly active catalyst system in aqueous medium. Chem Eng J 324:303-312

41. Zhang J, Bai X (2017) Microwave-assisted synthesis of Pd nanoparticles and their catalysis application for Suzuki cross-coupling reactions. Inorg Nano-Met Chem 47:672-676

42. Zhao Y, Baeza JA, Koteswara Rao N, Calvo L, Gilarranz MA, Li YD, Lefferts L (2014) Unsupported PVA- and PVP-stabilized $\mathrm{Pd}$ nanoparticles as catalyst for nitrite hydrogenation in aqueous phase. J Catal 318:162-169

43. Zhu J-F, Tao G-H, Liu H-Y, He L, Sun Q-H, Liu H-C (2014) Aqueous-phase selective hydrogenation of phenol to cyclohexanone over soluble Pd nanoparticles. Green Chem 16:2664-2669

44. Narayanan R, El-Sayed MA (2003) Effect of catalysis on the stability of metallic nanoparticles: Suzuki reaction catalyzed by PVP-palladium nanoparticles. J Am Chem Soc 125:8340-8347

45. Tarnowicz S, Alsalahi W, Mieczyńska E, Trzeciak AM (2017) Heck arylation of allyl alcohol catalyzed by $\operatorname{Pd}(0)$ nanoparticles. Tetrahedron 73:5605-5612

46. Uberman PM, Pérez LA, Martín SE, Lacconi GI (2014) Electrochemical synthesis of palladium nanoparticles in PVP solutions and their catalytic activity in Suzuki and Heck reactions in aqueous medium. RSC Adv 4:12330-12341

47. Rautiainen S, Chen J, Vehkamäki M, Repo T (2016) Oxidation of vanillin with supported gold nanoparticles. Top Catal 59:1138-1142

48. Bayer T, Milker S, Wiesinger T, Winkler M, Mihovilovic MD, Rudroff F (2017) In vivo synthesis of polyhydroxylated 
compounds from a "hidden reservoir" of toxic aldehyde species. ChemCatChem 9:2919-2923

49. Zhu Y, Liu J, Liao Y, Lv W, Ma L, Wang C (2018) Degradation of vanillin during lignin valorization under alkaline oxidation. Top Curr Chem 376:29

50. Wu M, Pang J-H, Song P-P, Peng J-J, Xu F, Li Q, Zhang X-M (2019) Visible light-driven oxidation of vanillyl alcohol in air with $\mathrm{Au}-\mathrm{Pd}$ bimetallic nanoparticles on phosphorylated hydrotalcite. New J Chem 43:1964-1971

51. Enache DI, Edwards JK, Landon P, Solsona-Espriu B, Carley AF, Herzing AA, Watanabe M, Kiely CJ, Knight DW, Hutchings GJ (2006) Solvent-free oxidation of primary alcohols to aldehydes using $\mathrm{Au}-\mathrm{Pd} / \mathrm{TiO}_{2}$ catalysts. Science 311:362-365

52. Chen G, Wu S, Liu H, Jiang H, Li Y (2013) Palladium supported on an acidic metal-organic framework as an efficient catalyst in selective aerobic oxidation of alcohols. Green Chem 15:230-235

53. Layek K, Maheswaran H, Arundhathi R, Kantam ML, Bhargava SK (2011) Nanocrystalline magnesium oxide stabilized palladium(0): an efficient reusable catalyst for room temperature selective aerobic oxidation of alcohols. Adv Synth Catal 353:606-616

54. Anderson M, Afewerki S, Berglund P, Córdova A (2014) Total synthesis of capsaicin analogues from lignin-derived compounds by combined heterogeneous metal, organocatalytic and enzymatic cascades in one pot. Adv Synth Catal 356:2113-2118

55. Hinde CS, Ansovini D, Wells PP, Collins G, Aswegen SV, Holmes JD, Hor TSA, Raja R (2015) Elucidating structure-property relationships in the design of metal nanoparticle catalysts for the activation of molecular oxygen. ACS Catal 5:3807-3816

56. Fu W, Yue L, Duan X, Li J, Lu G (2016) Acceptor-free dehydrogenation of 4-hydroxy-3-methoxybenzyl alcohol to vanillin over a palladium complex. Green Chem 18:6136-6142

57. Zhang Z, Khrouz L, Yin G, Andrioletti B (2019) Efficient oxidation of benzylic and aliphatic alcohols using a bioinspired crossbridged cyclam manganese complex with $\mathrm{H}_{2} \mathrm{O}_{2}$. Eur J Org Chem 2019:323-327

58. Dadras A, Naimi-Jamal MR, Moghaddam FM, Ayati SE (2018) Green and selective oxidation of alcohols by immobilized Pd onto triazole functionalized $\mathrm{Fe}_{3} \mathrm{O}_{4}$ magnetic nanoparticles. J Chem Sci 130:162

59. Lu Y-M, Zhu H-Z, Liu J-W, Yu S-H (2015) Palladium nanoparticles supported on titanate nanobelts for solvent-free aerobic oxidation of alcohols. ChemCatChem 7:4131-4136
60. Abad A, Almela C, Corma A, Garcia H (2006) Efficient chemoselective alcohol oxidation using oxygen as oxidant. Superior performance of gold over palladium catalysts. Tetrahedron 62:6666-6672

61. Buffin BP, Clarkson JP, Belitz NL, Kundu A (2005) Pd(II)-biquinoline catalyzed aerobic oxidation of alcohols in water. J Mol Catal A 225:111-116

62. Kim A, Bae HS, Park JC, Song H, Park KH (2015) Surfactantfree Pd@ $\mathrm{SiO}_{2}$ yolk-shell nanocatalysts for selective oxidation of primary alcohols to aldehydes. New J Chem 39:8153-8157

63. Olmos CM, Chinchilla LE, Cappella AM, Villa A, Delgado JJ, Hungria AB, Blanco G, Calvino JJ, Prati L, Chen X (2018) Selective oxidation of veratryl alcohol over $\mathrm{Au}-\mathrm{Pd} / \mathrm{Ce}_{0.62} \mathrm{Zr}_{0.38} \mathrm{O}_{2}$ catalysts synthesized by sol-immobilization: effect of $\mathrm{Au}: \mathrm{Pd}$ molar ratio. Nanomaterials 8:669/661-669/616

64. Yang Z-W, Zhao X, Li T-J, Chen W-L, Kang Q-X, Xu X-Q, Liang X-X, Feng Y, Duan H-H, Lei Z-q (2015) Catalytic properties of palygorskite supported $\mathrm{Ru}$ and $\mathrm{Pd}$ for efficient oxidation of alcohols. Catal Commun 65:34-40

65. Zhang L, Li P, Yang J, Wang M, Wang L (2014) Palladium supported on magnetic core-shell nanoparticles: an efficient and reusable catalyst for the oxidation of alcohols into aldehydes and ketones by molecular oxygen. ChemPlusChem 79:217-222

66. Mecozzi F, Dong JJ, Saisaha P, Browne WR (2017) Oxidation of vicinal diols to $\alpha$-hydroxy ketones with $\mathrm{H}_{2} \mathrm{O}_{2}$ and a simple manganese catalyst. Eur J Org Chem 2017:6919-6925

67. De Crisci AG, Chung K, Oliver AG, Solis-Ibarra D, Waymouth RM (2013) Chemoselective oxidation of polyols with chiral palladium catalysts. Organometallics 32:2257-2266

68. Steele AM, Zhu J, Tsang SC (2001) Noble metal catalyzed aerobic oxidation of alcohols to aldehydes in supercritical carbon dioxide. Catal Lett 73:9-13

69. Iwahama T, Yoshino Y, Keitoku T, Sakaguchi S, Ishii Y (2000) Efficient oxidation of alcohols to carbonyl compounds with molecular oxygen catalyzed by $\mathrm{N}$-hydroxyphthalimide combined with a Co species. J Org Chem 65:6502-6507

Publisher's Note Springer Nature remains neutral with regard to jurisdictional claims in published maps and institutional affiliations. 